\section{Potato Leafhopper Economic Injury Levels on Early- stage Snap and Dry Kidney Beans}

\author{
Thomas P. Kuhar, ${ }^{1}$ \\ Michael P. Hoffmann, ${ }^{2}$ \\ Lydia J. Stivers-Young, ${ }^{3}$ \\ Susan B. Sterrett, ${ }^{4}$ and \\ Michele Marini $^{5}$
}

Additional indeX words. Empoasca fabae, Phaseolus vulgaris, IPM, threshold

\begin{abstract}
Summary. Field cage experiments were conducted in Ithaca, N.Y. in 2001 to determine the yield effect of potato leafhopper (Empoasca fabae) infestations on early-stage beans (Phaseolus vulgaris). Yields of 'Hystyle' snap beans and 'Montcalm' dry kidney beans were significantly reduced when infested by potato leafhopper at the cotyledon, two-leaf, and four-leaf stages. For snap beans, no differences in yield response from potato leafhopper were observed among the three plant growth stages. For dry beans, there was a difference in yield response between cotyledon and fourleaf-stage plants. Dynamic economic injury levels for potato leafhopper on early-stage beans are suggested.
\end{abstract}

$\mathrm{P}$ otato leafhopper (PLH) is an important midsummer pest of beans and other crops in the eastern and midwestern U.S. Insect populations migrate northward each spring from warmer climates in the

\footnotetext{
The authors thank Jeffrey Gardner (Department of Entomology, Cornell University) and John Speese III (Eastern Shore Agricultural Research and Extension Center, Virginia Tech) for reviews of an earlier draft of this manuscript. This research was supported by a grant from the New York Vegetable Research Council and Association.

${ }^{1}$ Department of Entomology, Virginia Tech, Eastern Shore AREC, Painter, VA, 23420.

${ }^{2}$ Department of Entomology, Cornell University, Ithaca, NY 14853

${ }^{3}$ Pennsylvania State Cooperative Extension, Washington County, Washington, PA 15301

${ }^{4}$ Department of Horticulture, Virginia Tech, Eastern Shore AREC, Painter, VA, 23420.

${ }^{5}$ Department of Statistics, Virginia Tech, Blacksburg, VA, 24061-0439.
}

southern U.S. (Medler, 1957). PLH feeding and probing on leaves and stems causes cellular abnormalities, which result in a condition called hopperburn (Serrano and Backus, 1998). In beans, affected plants are often stunted, and exhibit bronzing and curling of leaves and/or necrosis of leaf margins. PLH feeding can also lead to reduced pod number, reduced number of seeds per pod, and reduced seed weight (van Schoonhoven et al., 1978). The level of damage (yield loss) resulting from PLH feeding is dependent upon a number of factors including: pest density (Gonzalez and Wyman, 1991); bean cultivar (Eckenrode, 1981; Lindgren and Coyne, 1995; Schaafsma et al., 1998); and plant growth stage at time of infestation (van Schoonhoven et al., 1978). Wolfenbarger (1963) observed more than a $50 \%$ reduction in snap bean yield when plants were not protected from PLH. Leafhopper feeding on lima beans in Maryland caused reductions of $5 \%$ to $14 \%$ in shelled seed yield (Eckenrode and Ditman, 1963); whereas, little to no yield reductions resulted from PLH infestations on 'Red Kloud' kidney beans in New York (Eckenrode, 1981).

Given the relatively high variability in plant response to PLH feeding insect injury, the development of science-based economic injury levels for PLH on edible beans has been difficult. In New York, an action threshold of $2 \mathrm{PLH}$ nymphs/leaf is recommended for all edible bean crops at pre-bloom stage (Reiners et al., 2002). In Wisconsin, Gonzalez and Wyman (1991) suggested a threshold of I PLH/leaf for snap beans with at least one true leaf. However, based on recent observations of snap beans in the field, it is thought that these thresholds maybe too high for plants attacked in the seedling stage or early in their growth development. Also, economic injury levels for crops should be dynamic and represent fluctuating market values and management costs (Pedigo et al., 1986). This is particularly important for edible bean crops because there is considerable range in the market value for fresh market beans compared with processing and dry beans. Therefore, the objectives of our study were to evaluate the effects of PLH density on yield of snap beans and dry kidney beans infested at early growth stages, and to develop economic injury levels for PLH that reflect fluctuating crop values and management costs.

\section{Materials and methods}

Field-CAGe eXPeriments. Studies were conducted at the Cornell University Research Farm near Freeville, N.Y. In June 2001, a 0.25-acre (0.101 ha) plot of land was prepared for planting, with fertilizer and herbicides applied according to commercial practices. Twelve cages, each $6 \mathrm{ft}$ ( 1.8 $\mathrm{m})$ wide $\times 12 \mathrm{ft}(3.7 \mathrm{~m})$ long $\times 5 \mathrm{ft}$ $(1.5 \mathrm{~m})$ tall, were installed. Cages were covered with nylon organdy [32 $\times 32$ mesh per inch $(81.3$ per $\mathrm{cm})]$ for confinement of PLH on infested plots and to prevent access of PLH to noninfested plots. Seeds of 'Hystyle' snap beans were sown in six of the cages and 'Montcalm' dark red kidney beans in the other six cages. To produce beans of different growth stages, seeds were sown on three planting dates (12 June, 20 June, and 2 July). Within each cage, nine randomized plots [ 1 row by $4 \mathrm{ft}$ $(1.2 \mathrm{~m})]$ were established representing three replications of each planting date. Seeds were spaced 3.9 inches (9.91 $\mathrm{cm}$ ) apart and seedlings thinned to a uniform density of 10 plants per plot. The experimental design was a split plot. The whole plot was completely randomized with PLH density as the whole plot factor. The split plot factor was plant growth stage arranged in a randomized complete block.

On 10 July, PLH were collected from a nearby alfalfa (Medicago sativa) field by vacuuming and sweep netting and released into the cages to establish a range of PLH densities (above and below the threshold). Plant growth stages at PLH infestation included cotyledon, two-leaf, and four-leaf stages resulting from the three different planting dates (representing 7, 17 and $27 \mathrm{~d}$ after planting, respectively). PLH densities were monitored weekly from 13 July to 13 Aug. by counting the number of adults and nymphs on five trifoliate leaves per plot. To verify that PLH did not exhibit a preference for any particular plant growth stage, differences in PLH densities among plant growth stages within a cage were analyzed using analysis of variance procedures (SAS, Cary, N.C.). PLH density data were square-root transformed prior to analysis.

After bloom of the last planting date in mid-August, cages were removed from the bean plots. At this 
time, natural PLH populations had declined in fields on the research farm, and on the plants within cages. Snap beans were harvested on 8 Aug., 16 Aug., and 24 Aug., which was about $65 \mathrm{~d}$ after each sowing. Marketable bean pods were hand-picked from all 10 plants per plot and weighed in the field. Yields were converted to tons per acre using a row spacing of $3 \mathrm{ft}(0.9$ $\mathrm{m})$. Kidney beans were harvested on 8 Oct. after all plants had dried down in the field. Pods were picked from plants in the field. Beans were removed from pods and weighed. Yields per plot were converted to lbs per acre using a row spacing of $3 \mathrm{ft}$.

For both bean species simple linear regression analysis of PLH density on yield was used to determine the overall nature of the relationship between the two variables for snap and kidney beans using PROC GLM procedure in SAS. An analysis of covariance using SAS general linear models (PROC GLM) was used to compare regression slopes between growth stages, where PLH density was declared as the covariate. Because of the potential yield effects from the field cages and different production practices used in our experiment, yield reductions were converted to proportion yield loss [ = (yield with no insects - yield with insects)/yield with no insects], and then expressed as typical yield loss based on a 3 -year average yield of snap beans [31.9 tons / acre (71.51 t.ha $\left.\left.\mathrm{h}^{-1}\right)\right]$ and kidney beans $\left[1,400 \mathrm{lb} /\right.$ acre $\left.\left(1,569.2 \mathrm{~kg} \cdot \mathrm{ha}^{-1}\right)\right]$ in New York (New York Agricultural Statistics Service, 2001). When the main effect of stage of growth was statistically significant, Fisher's protected LSD was performed as a post-hoc method to compare the main effects of stage of growth at application on yield.

ECONOMIC INJURY LEVELS. ECOnomic injury levels (EILs) for PLH on early-stage beans were expressed in number of PLH per 25 leaves (a standard sampling unit for scouting procedures). The general model for the EIL is EIL $=\mathrm{C} /$ VD' $\mathrm{K}$, where $\mathrm{C}=$ cost of control per production unit, $\mathrm{V}$ $=$ market value per production unit, $\mathrm{D}^{\prime}$ = yield loss per insect, and $\mathrm{K}=$ proportionate reduction of the insect population from control (Hunt et al., 2000; Pedigo et al., 1986). C was estimated to range from $\$ 10$ to $\$ 20$ per acre (\$24.71 to $\$ 49.42$ per ha)(Whittle, 2001). Market value (V) was estimated to range from $\$ 8$ to $\$ 12$ per $32-\mathrm{lb}$ (14.5-kg) bushel $(\$ 0.55$ to $\$ 0.83 / \mathrm{kg})$ for fresh market snap beans, $\$ 175$ to $\$ 200 /$ ton $(\$ 192.90$ to $\$ 220.46 / \mathrm{t}$ ) for processing snap beans, and $\$ 0.15$ to $\$ 0.20 / \mathrm{lb}$ ( $\$ 0.33$ to $\$ 0.44 / \mathrm{kg}$ ) for dry kidney beans based on a recent 3 year average (New York Agricultural Statistics Service, 2001). Values for D' were derived from the slopes of yield loss versus PLH density regressions. The value of $\mathrm{K}$ was estimated to be 0.9 based on recent insecticide efficacy trials on PLH (Kuhar et al., 2001; Stivers et al., 2001).

\section{Results}

FieLd-CAge eXPeriments. A density range of 0 to 8 PLH per leaf was established in the six cages of snap beans (Fig. 1A). The number of PLH per leaf was not affected by plant growth stage or the interaction of cage and growth stage. For the kidney beans, a range of 0 to 13 PLH per leaf was established in six cages (Fig. 1B). As with the snap beans, the number of PLH per leaf in the kidney beans was not affected by plant growth stage or the interaction of cage and growth stage. Thus, within cages, PLH did not exhibit a preference for plant growth stage from cotyledon to four-leaf stage.

There was a significant linear relationship between PLH density and fresh yield of snap beans $(F=13.59$; df $=1,4 ; P=0.02)$. Plant growth stage or the interaction of plant growth stage with PLH density did not af-

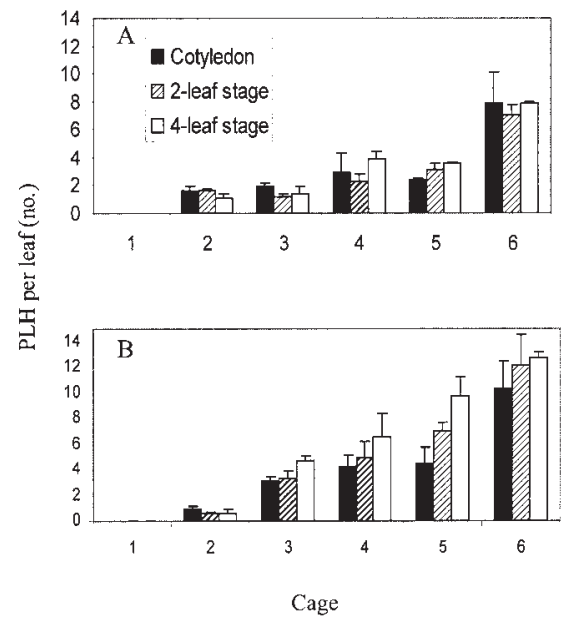

Fig. 1. Potato leaf hopper (PLH) densities on cotyledon, two-leaf, and four-leaf stage plants in (A) snap bean cages and (B) kidney bean cages. Vertical capped bars equal standard error. The number of PLH per leaf was not affected by plant growth stage or the interaction of cage and growth stage (analysis of variance, $P>0.05$ ). fect the aforementioned relationship. Therefore, data were pooled from the three plant growth stages and used for calculation of a single yield loss by PLH density graph (Fig. 2A). The resulting regression equation was $\mathrm{y}=0.4126 \mathrm{x}$; $r^{2}=0.73 ; P<0.005$, where $\mathrm{y}=$ yield loss in tons/acre and $\mathrm{x}=$ number of PLH per leaf.

Similarly for kidney beans, there was a significant effect of PLH density on dry bean yield $(F=20.63 ; \mathrm{df}=1$, 4; $P<0.01$. The interaction of PLH density and plant growth stage on yield was not significant, but the main effect of plant growth stage was significant $(F$ $=16.08 ; \mathrm{df}=2,8 ; P<0.01)$. PLH density had a greater effect on dry kidney bean yield when plants were infested at cotyledon than at four-leaf stage $(P$ $<0.05)$. However, because the interaction between PLH density and plant growth stage was not significant, and for practical reasons in developing the economic injury levels, dry bean yield loss data were pooled from the three plant growth stages. As with the snap beans, the pooled data were converted to percentage yield loss, then multiplied by a typical (3-year average) yield of dry beans (lb/acre) for New York. The resulting regression equation was $\mathrm{y}=$ $-10.74 \mathrm{x}^{2}+219.6 \mathrm{x} ; r^{2}=0.804 ; P<$ 0.005 (Fig. 2B).

ECONOMic InJURY LEVELs. Values for $\mathrm{D}^{\prime}$ in the equation, $\mathrm{EIL}=\mathrm{C} / \mathrm{VD}^{\prime} \mathrm{K}$, were derived from the slopes in Fig. 2A for snap beans and Fig. 2B for dry kidney beans. An EIL matrix for PLH
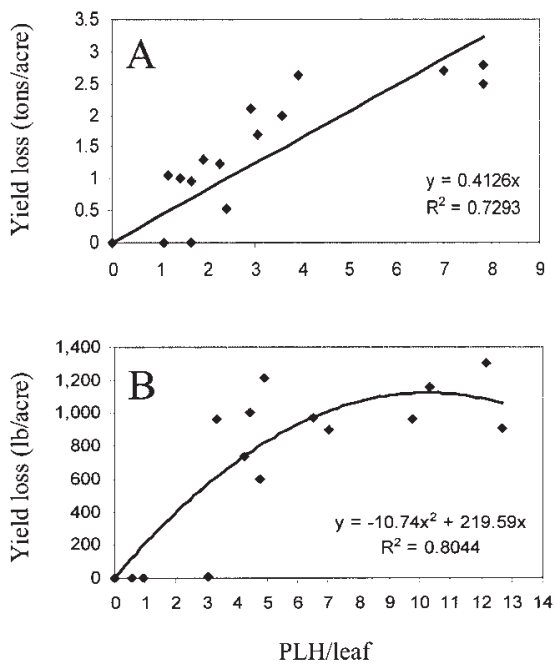

Fig. 2. Yield loss by potato leafhopper (PLH) density relationships for (A) snap beans and (B) dry kidney beans. Plants were infested at cotyledon through four-leaf stage; 1.0 ton $/$ acre = $2.24 \mathrm{t} \cdot \mathrm{ha}^{-1}, 1.0 \mathrm{lb} /$ acre $=1.12 \mathrm{~kg} \cdot \mathrm{ha}^{-1}$. 
Table 1. Economic injury levels (EIL) for potato leafhopper (PLH) on edible bean crops infested at cotyledon to four-leaf stage.

\begin{tabular}{lcc}
\hline & \multicolumn{2}{c}{$\begin{array}{c}\text { EIL (PLH/25 leaves) for } \\
\text { various control costs }(\mathbf{C})\end{array}$} \\
\cline { 2 - 3 } value $(\mathrm{V})$ & $\mathbf{\text { \$10/acre }}$ & $\mathbf{\$ 2 0 / \text { acre }}$ \\
\hline Snap beans, fresh market $(\$ / \text { bushel })^{\mathrm{z}}$ & & \\
8 & 1.3 & 2.7 \\
10 & 1.1 & 2.2 \\
12 & 0.9 & 1.9 \\
Snap beans, processing $(\$ / \text { ton })^{\mathrm{x}}$ & & 9.0 \\
150 & 4.5 & 7.7 \\
175 & 3.8 & 6.7 \\
200 & 3.4 & 17.7 \\
Dry beans, processing $(\$ / \mathrm{lb})^{\mathrm{w}}$ & & 14.8 \\
0.15 & 8.9 & 13.3 \\
0.18 & 7.4 & \\
0.20 & 6.6 & \\
\hline
\end{tabular}

${ }^{2} \$ 1.00 /$ bushel $=\$ 0.069 / \mathrm{kg}, 1$ bushel $=32 \mathrm{lb}(14.5 \mathrm{~kg})$.

v $\$ 1.00 /$ acre $=\$ 2.471 /$ ha.

× $\$ 1.00 /$ ton $=\$ 1.102 / \mathrm{t}$.

${ }^{\mathrm{w}} \$ 1.00 / \mathrm{lb}=\$ 2.205 / \mathrm{kg}$.

on early-stage fresh-market snap beans, processing snap beans, and dry kidney beans is presented in Table 1. Because of the wide range in market value for beans, the EIL varied considerably. EILs ranged from 1 to 3 PLH per 25 leaves for fresh market snap beans, 3 to $8 \mathrm{PLH} / 25$ leaves for processing snap beans, and 6 to $18 \mathrm{PLH} / 25$ leaves for kidney beans.

\section{Discussion}

Results of this study showed that potato leafhopper can have a significant impact on snap bean and kidney bean yield when infestations occur at an early plant growth stage. An action threshold of 1 or $2 \mathrm{PLH} / \mathrm{leaf}(=25$ to $50 \mathrm{PLH} / 25$ leaves), which is currently used in many states, is probably too high for snap and kidney beans infested at cotyledon through four-leaf stage. Because of the potential for rapid population buildup, and because of the dramatic yield effect that PLH can have on beans, we recommend that control measures should be taken at a threshold less than 0.5 PLH/leaf (=12/25 leaves) for plants at four-leaf stage or earlier. As an alternative, growers can apply a systemic insecticide treatment at planting to protect early-stage plants. More mature bean plants probably can sustain higher PLH numbers without significant yield effects (Gonzalez and Wyman, 1991). Bean cultivar, and additional plant stress factors, including climate and incidence of plant disease, also can affect yield response to potato leafhopper (Leath and Byers, 1977; Lindgren and Coyne, 1995; Schaafsma et al., 1998). These factors as well as market value of the crop and infestation levels of other insect pests such as bean leaf beetle, aphids, and thrips species should be considered in management decisions for potato leafhopper.

\section{Literature cited}

Eckenrode, C.J. 1981. Influence of potato leafhopper control on kidney beans in New York. J. Econ. Entomol. 74:510-513.

Eckenrode, C.J. and L.P. Ditman. 1963. An evaluation of potato leafhopper damage to lima beans. J. Econ. Entomol. 74: 510-513.

Gonzalez, A.L. and J.A. Wyman. 1991. Effect of varying potato leafhopper (Homoptera: Cicadellidae) population densities on snap bean yield. J. Econ. Entomol. 84: 644-649.

Hunt, T.E., L.G. Higley, and L.P. Pedigo. 2000. A Re-examination of economic injury levels for potato leafhopper (Homoptera: Cicadellidae) on soybean. J. Entomol. Sci. 32:97-104.

Kuhar, T.P., L.J. Stivers, A.G. Taylor, and M.P. Hoffmann. 2001. Potato leafhopper management in dry beans, 2000. Arthropod Management Tests. 26:E2.
Leath, K.T. and R.A. Byers. 1977. Interaction of fusarium root-rot with pea aphid and potato leafhopper on forage legumes. Phytopathology 67:226-229.

Lindgren, D.T. and D.P. Coyne. 1995. Injury and yield of leafhopper-infested dry beans. J. Amer. Soc. Hort. Sci. 120:839-842.

Medler, J.T. 1957. Migration of the potato leafhopper-A report on a cooperative study. J. Econ. Entomol. 50:493-497.

New York Agricultural Statistics Service. 2001. Vegetables 2000 annual summary. New York Agricultural Statistics Service. Seasonal Bull. No. 984-1-01.

Pedigo, L.P., S.H. Hutchins, and L.G. Higley. 1986. Economic injury levels in theory and practice. Annu. Rev. Entomol. 31:341-368

Reiners, S., C.H. Petzoldt, and M.P. Hoffmann. 2002. Integrated crop and pest management guidelines for commercial vegetable production. Cornell Coop. Ext. Pub. 23 Jun. 2002. >http:// www.nysaes.cornell.edu/recommends / <.

Schaafsma, A.W., C. Cardona, J.L. Kornegay, A.M. Wylde, and T.E. Michaels. 1998. Resistance of common bean lines to potato leafhopper (Homoptera: Cicadellidae). J. Econ. Entomol. 91:981-986.

Serrano, M.S. and E.A. Backus. 1998. Differences in cellular abnormalities induced by the probing behaviors of Empoasca kraemeri (Homoptera: Cicadellidae) on tolerant and susceptible common beans. J. Econ. Entomol. 91:1481-1491.

Stivers, L.J., T.P. Kuhar, A.G. Taylor, and M. P. Hoffmann. 2001. Potato leafhopper trials in snap beans, 2000. Arthropod Management Test. 26:E9.

Van Schoonhoven, A., L.A. Gomez, and F. Alvalos. 1978. The influence of leafhopper (Empoasca kraemeri) attack during various bean (Phaseolus vulgaris) plant growth stages on seed yield. Entomol. Expt. Appl. 23:115-120.

Whittle, B. 2001. Farm expenses: Where do you stand? Farm Business Management Update. Virginia Coop. Ext. Electronic Publication. 7 Jul. 2002. >http: //www.ext.vt.edu<.

Wolfenbarger,D.O. 1963. Control measures for the leafhopper Empoasca kraemeri on beans. J. Econ. Entomol. 56:417-419. 